\title{
Spectrofluorimetric determination of certain antidepressant drugs in human plasma
}

\author{
Mahmoud A Omar ${ }^{1 *}$, Osama H Abdelmageed ${ }^{2}$, Sayed M Derayea ${ }^{1}$, Tadayuki Uno ${ }^{3}$ and Tamer Z Atia ${ }^{1,3}$
}

\begin{abstract}
Background: Certain antidepressant drugs namely Sertraline hydrochloride, Fluoxetine hydrochloride, Paroxetine hydrochloride, Thioridazine hydrochloride and Amineptine hydrochloride were studied throughout this work using spectrofluorimetric method.

Methods: The spectrofluorimetric method is based on the charge-transfer reaction of these drugs as n-electron donors with 7,7,8,8-tetracyanoquinodimethane (TCNQ) as m-electron acceptor. The drug-TCNQ complexes showed excitation maxima ranged from 290-301 nm and emission maxima ranged from 443-460 nm.

Results and discussion: The different experimental parameters affecting the formation and stability of the complexes were carefully studied and optimized. The calibration plots were constructed over the range of 50-450 ng mL-1 for Fluoxetine and Sertraline, 50-550 ng mL-1 for Paroxetine, 50-650 ng mL-1 for Thioridazine and 50-750 ng mL-1 for Amineptine. The proposed method was validated according to ICH and USP guidelines with respect to specificity, linearity, accuracy, precision and robustness.

Conclusion: A simple, reliable, sensitive and selective spectrofluorimetric method has been developed for determination of certain antidepressant. The proposed method was successfully applied to the analysis of the cited drugs in dosage forms. The high sensitivity of the proposed method allows determination of investigated drugs in spiked and real human plasma.
\end{abstract}

Keywords: Antidepressant drugs,7,7,8,8-tetracyanoquinodimethane (TCNQ), Dosage forms, Human plasma, Spectrofluorimetric determination

\section{Background}

Depression: a common mental disorder is a chronic or recurrent illness that affects both economic and social functions of patients and can eventually lead to suicidal behaviors. Antidepressant medications have been used to treat all forms of major depressive disorders (Parfitt \& Martindale 2002). In the last years prescription of antidepressants has increased dramatically in Egypt. Sertraline, paroxetine, fluoxetine and amineptine are extensively used as antidepressant drugs in Egypt while thioridazine is a potent antipsychotic agent which is used in treatment of depression accompanied with anxiety. The chemical structures of the studied drugs in this work

\footnotetext{
* Correspondence: momar1971g@yahoo.com

${ }^{1}$ Analytical Chemistry Department, Faculty of pharmacy, Minia University, Minia 61519, Egypt

Full list of author information is available at the end of the article
}

are shown in Table 1. Several methods have been published for determination of these drugs in bulk or in different pharmaceutical formulations as well as in biological fluids. These methods include Volumetric methods (Bueno et al. 2000; Delazzeri 2005; Basavaiah et al. 1999), Spectroscopic methods (Onal et al. 2005; Darwish \& Refaat 2006; Patel et al. 2009; Darwish 2005; Mohamed et al. 2005; Mohamed et al. 2007), Electrochemical methods (Nouws et al. 2006; Atta-Politou et al. 2001), Chromatographic methods (Zainaghi et al. 2003; Nevado et al. 2006; Meiling et al. 2002; Sbarra et al. 1979, 1981; Tsaconas et al. 1989) and Capillary electrophoretic methods (Labat et al. 2002; Mandrioli et al. 2002).

The wide use of these drugs necessitates the development of simple, accurate, sensitive, applicable and cheaper method for their determination in pure forms, pharmaceutical formulations, spiked and real 
Table 1 Structural formula of the studied drugs

\begin{tabular}{lcl}
\hline Name & Chemical name \\
\hline Sertraline Hydrochloride & (15,4S)-4 [3,4-dichlorophenyl]- 1,2,3,4 \\
tetrahydro- $\mathrm{N}$-methyl-1-naphthylamine & (3S, 4R)-3-[(1,3-Benzodioxol-5-yloxy)methyl]- \\
\hline Paroxetine Hydrochloride & 4-(4-fluorophenyl) piperidine hydrochloride \\
\hline Fluoxetine Hydrochloride & (3RS)- $\mathrm{N}$-methyl-3-phenyl-3-[4-(trifluoromethyl) \\
phenoxy] propane-1-amine hydrochloride
\end{tabular}<smiles>CSc1ccc2c(c1)N(CCC1CCCCN1C)c1ccccc1S2</smiles><smiles>O=C(O)CCCCCCNC1c2ccccc2CCc2ccccc21</smiles>

human plasma. So this study describes a simple and very sensitive spectrofluorimetric method for determination of these drugs depending on the formation of charge-transfer complexes.

\section{Experimental and Methods Apparatus}

- A perkin Elmer LS 45 Luminescence spectrometer (United Kingdom) connected to an IBM PC computer loaded with FL WINLABTM software.

- SpectronicTM GenesysTM 2PC. Ultraviolet/Visible spectrophotometer (Milton Roy Co, USA) with matched $1 \mathrm{~cm}$ quartz cell connected to IBM computer loaded with winspecTM application software.

- Milwakee SM $101 \mathrm{pH}$ meter (Portugal).

- Digital analytical balance (AG 29, Meltter Toledo, Glattbrugg, Switzerland).

- Laboratory centrifuge 4000 rpm (Bremsen ECCO, Germany).

\section{Materials and reagents}

All materials were of analytical reagent grades and the solutions were prepared with double distilled water. Samples of investigated drugs were generously supplied by their 
respective manufacturers and were used without further purification; Sertraline hydrochloride was kindly provided by Pfizer Egypt, S.A.E., Cairo, Egypt. Fluoxetine hydrochloride was kindly provided by EIPICO, El Asher Ramadan City, Cairo, Egypt. Paroxetine hydrochloride was kindly provided by Pharaonia Pharmaceuticals Pharo Pharma, Alexandria, Egypt. Amineptine hydrochloride was kindly provided by Servier Egypt Industries Limited, 6th October City, Giza, Egypt and thioridazine hydrochloride was supplied by Delta Pharm, S.A.E, El Asher Ramadan City, Cairo, Egypt.

7,7,8,8-tetracyanoquinodimethane (TCNQ) (Sigma Chemical Co., USA) was prepared as $1 \times 10^{-3} \mathrm{M}$ in acetonitrile. Solution was found to be stable for at least one week at $4{ }^{\circ} \mathrm{C}$. Acetonitrile, diethyl ether and methanol (Riendel-De-Haen AG, Germany). Chloroform, 1, 2 Dichloromethane, Ethanol and 33\% W/V ammonia solution (El Nasr chemical Co., Abu Zabbal, Egypt).

Plasma was kindly provided by EL-Minia Hospital of Psychiatric medicine and kept frozen until assay.

\section{Pharmaceutical formulations}

The following available commercial preparations were analyzed; Lustral ${ }^{\circledR}$ tablets (Pfizer Egypt, S.A.E., Cairo, Egypt) labeled to contain $50 \mathrm{mg}$ sertraline per tablet. Flutin $^{\circledR}$ capsules (EIPICO, El Asher Ramadan City, Cairo, Egypt) labeled to contain $20 \mathrm{mg}$ Fluoxetine per capsule. Paxetin ${ }^{\circledR}$ tablets (Pharaonia Pharmaceuticals Pharo Pharma, Alexandria, Egypt) labeled to contain $20.0 \mathrm{mg}$ of paroxetine per tablet. Survector ${ }^{\circledR}$ tablets (Servier Egypt Industrial Limited, 6th October City, Giza, Egypt) labeled to contain $100.0 \mathrm{mg}$ of Amineptine hydrochloride per tablet. Thiozine ${ }^{\circledR}$ tablets (Delta Pharm, S.A.E, El Asher Ramadan City, Cairo, Egypt) labeled to contain $100 \mathrm{mg}$ of Thioridazine hydrochloride per tablet.

\section{Preparation of standard solutions}

An accurately weighed $20.0 \mathrm{mg}$ salt of each investigated drugs, was transferred into $125-\mathrm{mL}$ separating funnel containing about $20 \mathrm{~mL}$ of distilled water. The resultant solution was rendered distinctly alkaline with dropwise addition of $33 \% \mathrm{w} / \mathrm{v}$ aqueous ammonia solution. The librated free base was extracted with three potions of $5 \mathrm{~mL}$ chloroform. The combined chloroformic extracts were filtered through anhydrous sodium sulfate supported on Whitman filter paper. The filter paper was washed thoroughly with two portions of $5 \mathrm{~mL}$ chloroform. The combined extracts and washings were diluted to volume with chloroform to provide a stock standard solution containing $200.0 \mu \mathrm{g} \mathrm{mL} \mathrm{m}^{-1}$. This solution was further diluted with the same solvent to prepare working standard solutions containing $0.50-4.50 \mu \mathrm{gL}^{-1}$ of fluoxetine and sertraline, $0.50-5.5 \mu \mathrm{g} \mathrm{mL}^{-1}$ of paroxetine, 1.0-6.5 $\mu \mathrm{g} \mathrm{mL} \mathrm{m}^{-1}$ of thioridazine and $1.0-7.5 \mu \mathrm{g} \mathrm{mL} \mathrm{m}^{-1}$ of amineptine. The standard solutions were stable for seven days when kept in the refrigerator.

\section{General analytical procedure}

Into a series of $10 \mathrm{~mL}$ volumetric flasks, $1.0 \mathrm{~mL}$ of working standard solution of each drug was transferred over the cited concentration. One $\mathrm{mL}$ of $1 \times 10^{-3} \mathrm{M}$ TCNQ solution was added and mixed well. The reaction mixture was allowed to stand at room temperature (25.0 \pm $5^{\circ} \mathrm{C}$ ) for $40 \mathrm{~min}$ for fluoxetine, sertraline and paroxetine; $35 \mathrm{~min}$ for thioridazine and $45 \mathrm{~min}$ for amineptine then completed to the mark with chloroform. The fluorescence intensity of the complexes was measured at 443 , 447, 447, 450 and $458 \mathrm{~nm}$ after excitation at 290, 291, 291, 295 and $301 \mathrm{~nm}$ for fluoxetine, sertraline, paroxetine, amineptine and thioridazine respectively. Blank experiment was carried out simultaneously. The relative fluorescence intensity of each sample solution for each investigated drugs was accurately measured and plotted against the final drug concentration $\left(\mathrm{ng} \mathrm{mL}^{-1}\right)$ to get the calibration graphs.

\section{Procedure for pharmaceutical formulations (tablets and capsules)}

A quantity of finely powdered twenty tablets or mixed capsules contents equivalent to $100.0 \mathrm{mg}$ of active component was transferred to $50-\mathrm{mL}$ volumetric flask, sonicated for about 10 minute with about $30 \mathrm{~mL}$ double distilled water. The volume was made up with distilled water, mixed well and filtered. The first portion of the filtrate was discarded; twenty $\mathrm{mL}$ of the clear solution was transferred quantitatively to a $125 \mathrm{~mL}$ separating funnel. The contents of the funnel were rendered alkaline with dropwise addition 33\% w/v aqueous ammonia solution, and the procedure was completed as described under preparation of the standard solutions.

\section{Procedure for spiked human plasma}

$5.0 \mathrm{~mL}$ of drug free human blood sample was taken from three healthy volunteers into a heparinized tubes, centrifuged at $3000 \mathrm{rpm}$ for 30 minutes then $1.0 \mathrm{~mL}$ of the drug free plasma (supernatant) was spiked with $1.0 \mathrm{~mL}$ of investigated drugs containing $5.0-45.0 \mu \mathrm{g} \mathrm{mL}^{-1}$ of fluoxetine and sertraline, 5.0- $55.0 \mu \mathrm{g} \mathrm{mL} \mathrm{m}^{-1}$ of paroxeine, $10.0-65.0 \mu \mathrm{g} \mathrm{mL}^{-1}$ of thioridazine and 10.0$75.0 \mu \mathrm{g} \mathrm{mL}^{-1}$ of amineptine. $2.0 \mathrm{~mL}$ of acetonitrile was added as precipitating agent for protein then centrifuged at $4000 \mathrm{rpm}$ for about $20 \mathrm{~min}$. The supernatant was rendered alkaline by adding $1.0 \mathrm{~mL}$ of $33 \% \mathrm{w} / \mathrm{v}$ aqueous ammonia and then extract the librated free base three times with $3 \times 3 \mathrm{~mL}$ of chloroform. The combined chloroformic extracts were filtered through anhydrous sodium sulfate supported on Whitman filter paper. The filter paper was washed thoroughly with two portions of 


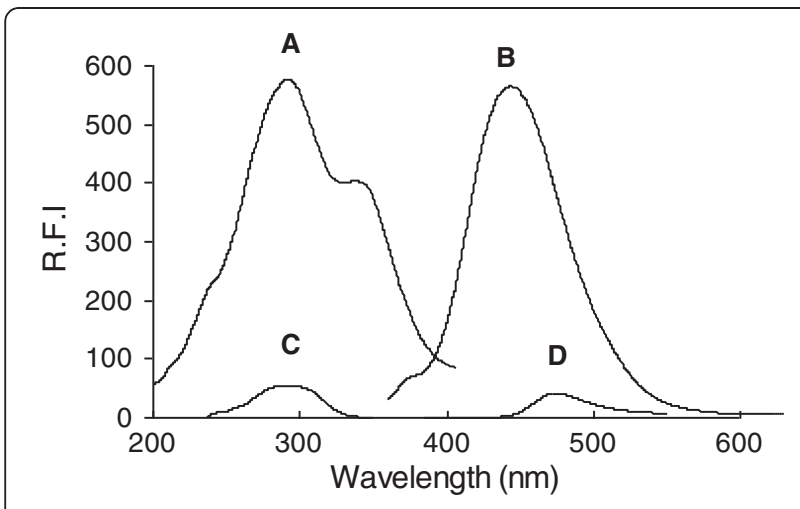

Figure 1 Fluorescence spectra of the produced CT-complex of fluoxetine $\left(450 \mathrm{ngml}^{-1}\right)$ with $1 \times 10^{-3} \mathrm{M}$ TCNQ where; A) Excitation spectrum B) Emission spectrum, C) Excitation spectrum of blank and D) Emission spectrum of blank.

$5 \mathrm{~mL}$ chloroform. The combined extracts and washings were diluted to volume with chloroform. Aliquotes covering the working concentration range was transferred into $10-\mathrm{mL}$ volumetric flasks; then the general procedure was followed. A blank value was determined by treating the drug free blood sample in the same manner.

\section{Procedure for real human plasma}

For fluoxetine, $20.0 \mathrm{mg}$ was taken orally once daily by three healthy human volanteers for 4 weeks. $5.0 \mathrm{~mL}$ of human blood sample was taken by using heperanized tube after an average of $6 \mathrm{hrs}$ following the last oral administration and centrifuged at $3000 \mathrm{rpm}$ for 30 minute. $3.0 \mathrm{~mL}$ of plasma obtained was treated with $2.0 \mathrm{~mL}$ of acetonitrile as precipitating agent for protein then centrifuged at $4500 \mathrm{rpm}$ for about 20 minute. The supernatant was rendered alkaline by adding $1.0 \mathrm{~mL}$ of $33 \% \mathrm{w} / \mathrm{v}$ aqueous ammonia followed by extraction with $3 \times 3 \mathrm{~mL}$ of chloroform. The combined extracts were diluted to volume with chloroform; then the general procedure was followed.

For paroxetine, $40.0 \mathrm{mg}$ was taken orally once daily by three healthy human volanteers for 14 days. $10.0 \mathrm{~mL}$

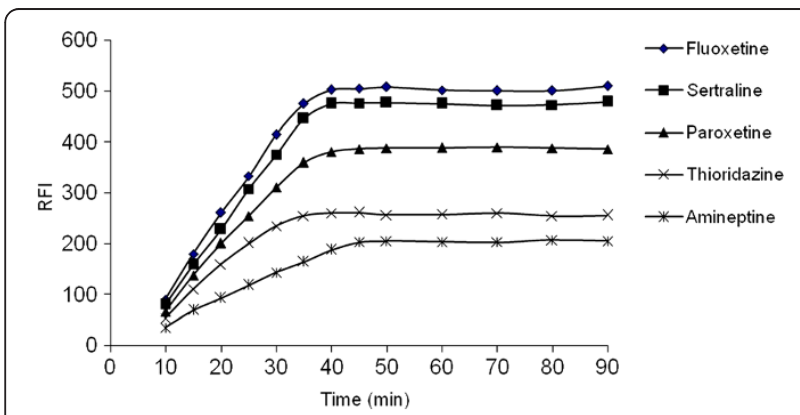

Figure 2 Effect of reaction time on the RFI of the reaction product using TCNQ and $350 \mathrm{ng} \mathrm{mL-1}$ of the studied drugs.

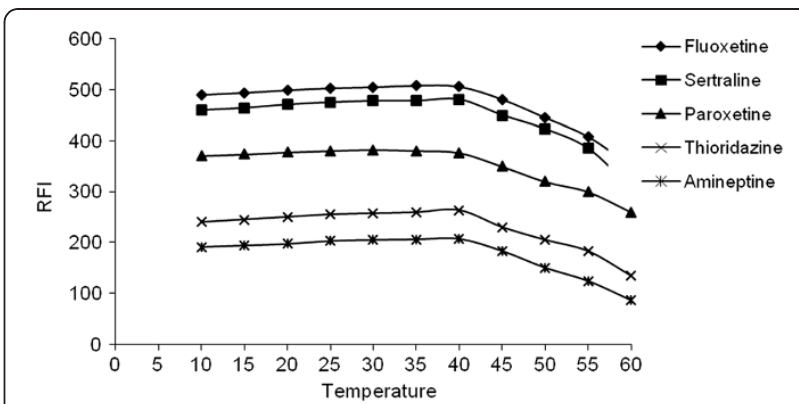

Figure 3 Effect of temperature on the RFI of the reaction product using TCNQ and $350 \mathrm{ng} \mathrm{mL-1}$ of the studied drugs.

of human blood sample was taken by using heperanized tube after an average of $12 \mathrm{hrs}$ following the last oral administration and centrifuged at $3000 \mathrm{rpm}$ for 30 minute. $6.0 \mathrm{~mL}$ of plasma obtained was treated with $4.0 \mathrm{~mL}$ of acetonitrile as precipitating agent for protein then centrifuged at $4500 \mathrm{rpm}$ for about 20 minute; then the procedure was followed as described for fluoxetine starting from "The supernatant was rendered alkaline by...".

For bupropion, $150.0 \mathrm{mg}$ was taken orally every $12 \mathrm{hrs}$ by three healthy human volanteers for 14 days. $5.0 \mathrm{~mL}$ of human blood sample was taken by using heperanized tube after an average of 6 hrs following the last oral administration; then the procedure was followed as described for fluoxetine.

For sertraline, $50.0 \mathrm{mg}$ was taken orally once daily by three healthy human volanteers for 14 days. $5.0 \mathrm{~mL}$ of human blood sample was taken by using heperanized tube after an average of $12 \mathrm{hrs}$ following the last oral administration; then the procedure was followed as described for fluoxetine.

For thioridazine, $100.0 \mathrm{mg}$ was taken orally four times daily by three healthy human volunteers for 7 days. $5.0 \mathrm{~mL}$ of human blood sample was taken by using heperanized tube at 8 th day, 3 hrs after the last morning oral administration; then the procedure was followed as described for fluoxetine.

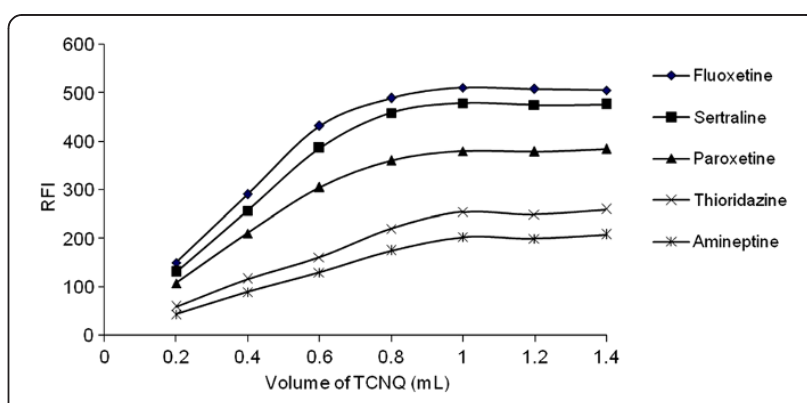

Figure 4 Effect of $1 \times 10-3 \mathrm{M}$ TCNQ volume on its reaction with $350 \mathrm{ng} \mathrm{mL}-1$ of the studied drugs. 


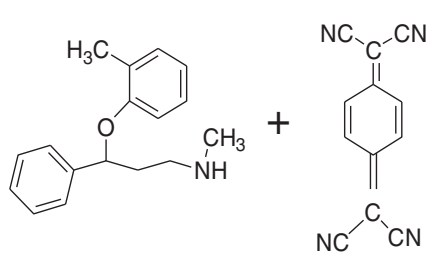

Fluoxetine

TCNQ

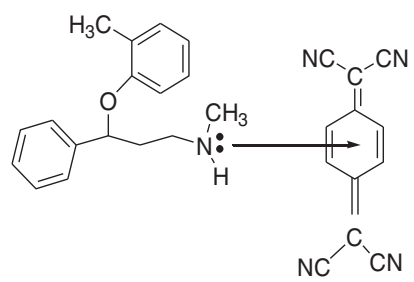

Charge transfere complex

Figure 5 The suggested reaction pathway between fluoxetine as representative example of the studied drugs with TCNQ.

\section{Results and discussion}

The aim of this work is to establish a simple, sensitive, reliable, selective and cheap spectrofluorimetric method for the analysis of investigated drugs in pure forms, pharmaceutical formulations, spiked and real human plasma. The developed method was based on reaction of investigated drugs with 7,7,8,8-tetracyanoquinodimethane (TCNQ) to form highly fluorescent product, measured fluorometrically.

\section{Fluorescence spectrum}

Solutions of the studied drugs have very weak native fluorescence intensity, however in presence of $\mathrm{TCNQ}$, the fluorescence intensity increases substantially. The formed CT complexes between the investigated drugs and TCNQ were probably through the lone pair of electron donated by the $\mathrm{N}$ atom in investigated drugs ( $\mathrm{n}$-donor) to TCNQ ( $\pi$-acceptor). The fluorescence intensity of the reaction product was measured at 443,447, 447, 450 and $458 \mathrm{~nm}$ after excitation at 290, 291, 291, 295 and $301 \mathrm{~nm}$ for fluoxetine, sertraline, paroxetine, amineptine and thioridazine respectively. Figure 1 shows the fluorescence spectra of the reaction product of fluoxetine as a representative example of investigated drugs TCNQ.

\section{Optimization of variables}

The spectrofluorimetric properties of the fluorescent product as well as the different experimental parameters affecting the development and stability of the CT-complex were carefully studied and optimized. Each factor was changed individually while the others were kept constant.
The studied factors include diluting solvent, reaction time, temperature and concentration of the reagent.

In order to select the suitable solvent for CT-complex formation, the reaction of TCNQ with studied drugs was carried out in different solvents. The studied solvents are chloroform, acetonitrile, ethanol, methanol and 1,2-dichloroethane. It was found that chloroform was considered to be the best solvent for the fluorescence development proved by the highest RFI observed relative to other solvents.

The fluorescence intensity of the formed CT-complex was monitored at different time intervals. It was found that complete fluorescence developments were attained after 40 minutes for fluoxetine, sertraline and paroxetine; after $35 \mathrm{~min}$ for thioridazine and after $45 \mathrm{~min}$ for amineptine (Figure 2). The fluorescence intensity remained stable for at least 2 hours.

The effect of temperature on the formed charge transfer complexes was studied in the range of $10-60^{\circ} \mathrm{C}$. All the formed complexes were stable up to $40^{\circ} \mathrm{C}$. At temperature higher than $40^{\circ} \mathrm{C}$, the RFI decreases probably due to dissociation of the complex. Thus, the determinations of studied drugs were carried out at $25 \pm 5^{\circ} \mathrm{C}$ (Figure 3).

Different volumes of $1 \times 10^{-3} \mathrm{M}$ of TCNQ reagent were used ranging from 0.2 to $1.4 \mathrm{~mL}$. It was observed that the relative fluorescence intensity (RFI) increases by increasing volume of TCNQ and reaches its maximum values at $1 \mathrm{~mL}$ of $1 \times 10^{-3} \mathrm{M}$ of TCNQ after which no further increase in RFI was observed. So $1 \mathrm{~mL}$ of $1 \times 10^{-3} \mathrm{M}$ of TCNQ was chosen as an optimum concentration for further investigation (Figure 4).

Table 2 Analytical parameters of spectrofluorimetric determination of investigated drugs with TCNQ

\begin{tabular}{|c|c|c|c|c|c|c|c|}
\hline $\begin{array}{l}\text { Investigated } \\
\text { drugs }\end{array}$ & $\begin{array}{l}\text { Linear range } \\
\qquad \mathrm{ng} \mathrm{mL}^{-1}\end{array}$ & $\begin{array}{l}\text { Intercept } \\
\text { (a) }\end{array}$ & $\begin{array}{l}\text { Standard deviation of } \\
\text { intercept (Sa) }\end{array}$ & $\begin{array}{l}\text { Slope } \\
\text { (b) }\end{array}$ & $\begin{array}{l}\text { Correlation } \\
\text { coefficient }(r)\end{array}$ & $\begin{array}{c}\text { LOD } \\
\mathrm{ng} \mathrm{mL^{-1 }}\end{array}$ & $\begin{array}{l}\mathrm{LOQ} \\
\mathrm{ng} \mathrm{\textrm {mL } ^ { - 1 }}\end{array}$ \\
\hline Fluoxetine & $50-450$ & -0.20 & 2.58 & 1.45 & 0.9995 & 5.35 & 17.85 \\
\hline Sertraline & $50-450$ & -2.18 & 2.82 & 1.36 & 0.9998 & 6.23 & 20.77 \\
\hline Paroxetine & $50-550$ & 0.63 & 2.45 & 1.10 & 0.9997 & 6.68 & 22.26 \\
\hline Thioridazine & $100-650$ & -1.47 & 2.68 & 0.71 & 0.9992 & 11.37 & 37.90 \\
\hline Amineptine & $100-750$ & -0.43 & 2.37 & 0.57 & 0.9990 & 12.48 & 41.61 \\
\hline
\end{tabular}


Table 3 Evaluation of accuracy of the investigated analytical procedure at three concentration levels within the specified range

\begin{tabular}{|c|c|c|c|}
\hline Drug & $50.0 \mathrm{ng} \mathrm{mL}^{-1}$ & Recovery $\%^{\mathrm{a}} 250.0 \mathrm{ng} \mathrm{mL}^{-1}$ & $450.0 \mathrm{ng} \mathrm{mL}^{-1}$ \\
\hline Fluoxetine & $100.94 \pm 1.29$ & $99.80 \pm 0.51$ & $100.41 \pm 0.28$ \\
\hline \multirow[t]{2}{*}{ Sertraline } & $99.84 \pm 1.69$ & $98.91 \pm 0.55$ & $100.14 \pm 0.30$ \\
\hline & $50.0 \mathrm{ng} \mathrm{mL}^{-1}$ & Recovery $\%^{\text {a }} 250.0 \mathrm{ngmL}^{-1}$ & $550.0 \mathrm{ngmL}^{-1}$ \\
\hline \multirow[t]{2}{*}{ Paroxetine } & $100.92 \pm 1.28$ & $100.09 \pm 0.67$ & $100.06 \pm 0.31$ \\
\hline & $100.0 \mathrm{ngmL}^{-1}$ & Recovery $\%^{\mathrm{a}} 350.0 \mathrm{ngmL}^{-1}$ & $650.0 \mathrm{ngmL}^{-1}$ \\
\hline \multirow[t]{2}{*}{ Thioridazine } & $100.44 \pm 1.57$ & $101.31 \pm 0.95$ & $100.48 \pm 0.41$ \\
\hline & $100.0 \mathrm{ngmL}^{-1}$ & Recovery $\%^{a} 450.0 \mathrm{ngmL}^{-1}$ & $750.0 \mathrm{ngmL}^{-1}$ \\
\hline Amineptine & $100.14 \pm 1.87$ & $98.81 \pm 0.72$ & $100.47 \pm 0.44$ \\
\hline
\end{tabular}

${ }^{\mathrm{a}}$ Mean of Six replicate measurements.

\section{Stoichiometry and Mechanism of the reaction}

The stoichiometric of the reaction mechanism was studied adopting the job's method (Job 1964) of continuous variation. The molar ratio of TCNQ to each of investigated drugs was 1:1. The reaction pathway proposed in Figure 5 is presented.

\section{Validation of the proposed method}

Concentration range (Topic Q2A 1994) was established by confirming that the analytical procedure provided a suitable degree of precision, accuracy and linearity when applied to the sample containing amount of analyte within or at the extreme of the specified range of the analytical procedure (Topic Q2B 1996; The United States Pharmacopoeia XXV and NF XX 2002). In this work, concentration ranging from 50 to $450 \mathrm{ng} \mathrm{mL}^{-1}$ (for fluoxetine and sertraline), 50 to $550 \mathrm{ng} \mathrm{mL}^{-1}$ (for

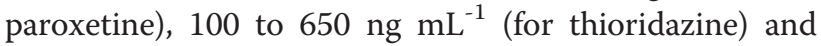
100 to $750 \mathrm{ng} \mathrm{mL}^{-1}$ (for amineptine) were studied. The whole set of experiments were carried out within this range to ensure the validation of the proposed procedure. Linear calibration graphs were obtained for all the studied drugs by plotting the RFI of the studied drugs versus the drug concentration $\left(\mathrm{ng} \mathrm{mL}^{-1}\right)$ within the specified range.

Linearity was indicated by high correlation coefficient obtained. The correlation coefficients $(r)$ of the formed products were in the range 0.9990 to 0.9998 indicating good linearity, as shown in Table 2.

Accuracy (The United States Pharmacopoeia XXV and NF XX 2002) was checked at three concentration levels within the specified range. Six replicate measurements were recorded at each concentration level. The results were expressed as percent recovery \pm standard deviation (Table 3). The obtained results show the close agreement between the measured and true values. Meanwhile, comparison of the obtained results from the analysis of the drug products by the proposed procedure with those obtained from the reported methods (Darwish 2005; Mohamed et al. 2005, 2007) revealed that their is no significant difference between them with respect to accuracy as indicated by $t$ - and F- tests (Table 4).

Precision (The United States Pharmacopoeia XXV and NF XX 2002) was checked at three concentration levels, eight replicate measurements were recorded at each concentration level; the results are summarized in Table 5. The calculated relative standard deviations were below $2.2 \%$ indicating excellent precision of the proposed procedure at both levels of repeatability and intermediate precision.

Limit of detection (Topic Q2A 1994) was calculated based on standard deviation of response and the slope of calibration curve (Topic Q2B 1996). The limit

Table 4 Statistical analysis of the results obtained using the proposed procedures and reference method for spectrofluorimetric analysis of authentic samples using TCNQ

\begin{tabular}{lcccc}
\hline \multicolumn{1}{c}{ Drug } & \multicolumn{2}{c}{ \% Recovery \pm SD } & t-value $^{\mathbf{b}^{\mathbf{2}}}$ & \\
\cline { 2 - 5 } & Proposed methods & Reported method ${ }^{\#}$ & 0.62 & F-value $^{\mathbf{b}}$ \\
\hline Fluoxetine & $100.34 \pm 0.89$ & $99.95 \pm 1.08$ & 0.06 & 1.44 \\
Sertraline & $99.61 \pm 1.57$ & $99.67 \pm 1.61$ & 0.13 & 1.05 \\
Paroxetine & $99.29 \pm 1.02$ & $99.38 \pm 1.20$ & 0.09 & 1.09 \\
Thiridazine & $100.32 \pm 1.24$ & $100.39 \pm 1.30$ & 0.23 & 2.63 \\
Amineptine & $100.37 \pm 1.04$ & $100.57 \pm 1.69$ & & \\
\hline
\end{tabular}

${ }^{\mathrm{b}}$ Tabulated value at $95 \%$ confidence limit; $\mathrm{F}=6.338$ and $t=2.306$.

\#References (Darwish 2005; Mohamed et al. 2005, 2007). 
Table 5 Evaluation of precision of the proposed spectrofluorimetric method for the determination of the investigated drugs

\begin{tabular}{ccccc}
\hline Drug & Conc. $\boldsymbol{\mu g} / \mathbf{m l}$ & Mean $^{\mathbf{c}}$ & S.D & RSD \\
\hline Fluoxetine & 50 & 100.84 & 1.33 & 1.32 \\
& 250 & 98.81 & 0.62 & 0.63 \\
& 450 & 100.47 & 0.41 & 0.41 \\
\hline Sertraline & 50 & 99.77 & 1.50 & 1.50 \\
& 250 & 98.87 & 0.50 & 0.51 \\
& 450 & 100.17 & 0.28 & 0.27 \\
\hline Paroxetine & 50 & 100.71 & 1.32 & 1.31 \\
& 250 & 100.14 & 0.69 & 0.69 \\
& 550 & 100.08 & 0.28 & 0.28 \\
\hline Thioridazine & 100 & 100.86 & 1.58 & 1.57 \\
& 350 & 101.31 & 0.76 & 0.75 \\
& 650 & 100.46 & 0.37 & 0.37 \\
\hline Amineptine & 100 & 100.10 & 1.84 & 1.84 \\
& 450 & 98.77 & 0.65 & 0.66 \\
& 750 & 100.53 & 0.39 & 0.39 \\
\hline
\end{tabular}

${ }^{C}$ mean is average of eight determinations.

of detection was expressed as (The United States Pharmacopoeia XXV and NF XX 2002):

$$
\mathrm{LOD}=3 \sigma / S
$$

Where $\sigma$ is the standard deviation of intercept. $\mathrm{S}$ is the slope of calibration curve.

The results are summarized in Table 2. The calculated detection limits for all the studied drugs were less than $12.48 \mathrm{ng} \mathrm{mL}^{-1}$ indicating good sensitivity of the proposed method.

Limit of quantitation (Topic Q2A 1994) was calculated based on standard deviation of intercept and slope of calibration curve. In this method, the limit of quantitation is expressed as (The United States Pharmacopoeia XXV and NF XX 2002):

$$
\mathrm{LOQ}=10 \sigma / S
$$

The calculated quantitation limits for all the studied drugs were all less than $41.61 \mathrm{ngmL}^{-1}$, as shown in Table 2, indicating good sensitivity of the proposed method. So it can be applied for analysis of drug in biological fluids.

\section{Specificity and interference}

The specificity of the method was investigated by observation of any interference encountered from the common tablet excipients, such as talc, starch, gum acacia, lactose and magnesium stearate. This study indicates that the presence of these excipients did not interfere with the proposed method as proved by the excellent recoveries obtained, as shown in Table 6.

\section{Application to pharmaceutical dosage forms}

The proposed method was applied for determination of investigated drugs in commercial pharmaceutical dosage forms. The results were statistically compared with those of reported methods (Darwish 2005; Mohamed et al. $2005,2007)$, in respect to accuracy and precision. The obtained mean recovery values were 100.62-101.01 \pm $0.66-1.39 \%$, as shown in Table 7. According to t- and F- tests, no significant difference was found between the proposed and reported methods at 95\% confidence level. This indicates good level of precision and accuracy.

\section{Application to spiked human plasma}

The high sensitivity attained by the proposed method allowed the determination of the studied drugs in spiked human plasma. The concentrations of investigated CNS drugs were computed from their corresponding regression equations. The obtained mean recovery values of the obtained amount were 99.76-100.39 $\pm 1.33-1.99 \%$ (Table 8).

\section{Analysis of cited drugs in real human plasma}

Fluoxetine is metabolized into its active metabolite norfluoxetine (Lemberger et al. 1985). Norfluoxetine concentrations are approximately equal to those of the parent drug during chronic therapy (Brunswick et al. 2002a). After a fixed daily dose of fluoxetine $\left(20.0 \mathrm{mg} \mathrm{day}^{-1}\right)$, the

Table 6 Analysis of the investigated drugs $\left(100.0 \mathrm{ng} \mathrm{mL}^{-1}\right)$ in presence of some common excipients using the proposed spectrofluorimetric method

\begin{tabular}{ccccccc}
\hline Excipients & $\begin{array}{c}\text { Amount Added } \\
\boldsymbol{\mu g m L}^{-1}\end{array}$ & Fluoxetine & Sertraline & Paroxetine & Thioridazine & Amineptine \\
\cline { 2 - 7 } & 50 & $100.07 \pm 0.61$ & $99.19 \pm 0.72$ & $99.85 \pm 0.87$ & $100.80 \pm 0.78$ & $101.29 \pm 0.79$ \\
Starch & 50 & $98.21 \pm 0.91$ & $99.83 \pm 0.63$ & $98.78 \pm 0.61$ & $100.73 \pm 0.71$ & $98.12 \pm 0.45$ \\
Lactose & 50 & $101.25 \pm 0.54$ & $98.24 \pm 1.25$ & $101.58 \pm 1.61$ & $99.86 \pm 0.33$ & $101.62 \pm 1.07$ \\
Mg stearate & 50 & $99.25 \pm 0.59$ & $99.76 \pm 1.01$ & $98.82 \pm 0.86$ & $100.28 \pm 0.89$ & $101.98 \pm 0.49$ \\
Gum acacia & 50 & $100.38 \pm 1.58$ & $100.18 \pm 0.25$ & $98.21 \pm 0.67$ & $99.70 \pm 0.51$ & $99.81 \pm 0.34$ \\
Talc & & & & &
\end{tabular}

${ }^{\mathrm{d}}$ Average of three determinations. 
Table 7 Statistical analysis of the results obtained using the proposed spectrofluorimetric and reported methods for analysis of the investigated drugs in pharmaceutical dosage forms

\begin{tabular}{|c|c|c|c|}
\hline Drug & $\begin{array}{l}\text { Pharmaceutical } \\
\text { dosage forms }\end{array}$ & $\begin{array}{c}\text { Proposed } \\
\text { method } \pm \text { SD } \\
(n=5)\end{array}$ & $\begin{array}{c}\text { Reported } \\
\text { methods }{ }^{8-10} \pm S D \\
(n=5)\end{array}$ \\
\hline \multirow[t]{2}{*}{ Fluoxetine } & Neurazine ${ }^{\circledast \text { tablets }}$ & $100.94 \pm 1.390$ & $100.53 \pm 1.46$ \\
\hline & & $\mathrm{t}=0.45^{\mathrm{e}} \mathrm{F}=1.09^{\mathrm{e}}$ & \\
\hline \multirow[t]{2}{*}{ Sertraline } & Thiozine ${ }^{\circledast}$ tablets & $100.18 \pm 1.15$ & $100.13 \pm 1.68$ \\
\hline & & $t=0.06 F=2.13$ & \\
\hline \multirow[t]{2}{*}{ Paroxetine } & Stellasil $^{\mathbb{m}}$ tablets & $100.01 \pm 1.196$ & $99.98 \pm 0.95$ \\
\hline & & $t=0.04 F=1.59$ & \\
\hline \multirow[t]{2}{*}{ Thioridazine } & Tryptizol $^{10}$ tablets & $100.62 \pm 0.663$ & $100.22 \pm 1.07$ \\
\hline & & $\mathrm{t}=0.71 \mathrm{~F}=2.59$ & \\
\hline \multirow[t]{2}{*}{ Amineptine } & Survector ${ }^{10}$ capsules & $100.14 \pm 1.26$ & $99.88 \pm 1.59$ \\
\hline & & $t=0.29 F=1.59$ & \\
\hline
\end{tabular}

${ }^{\mathrm{e}}$ Tabulated value at $95 \%$ confidence limit; $\mathrm{F}=6.338$ and $t=2.306$.

concentration of the drug and its active metabolite in the blood continued to grow through the first few weeks of treatment, and their steady concentration in the blood is achieved only after four weeks (Pérez et al. 2001; Brunswick et al. 2002b). Paroxetine is completely absorbed after oral administration and metabolized in the liver forming three main metabolites: the two isomers (3S,4R)-4-(4-fluorophenyl)- 3-[(4-hydroxy-3-methoxyphenoxy)methyl]-piperidine (M1), (3S,4R)-4-(4-fluorophenyl)3-[(3-hydroxy-4-methoxyphenoxy)methyl]-piperidine(M2) and (3S,4R)-3-hydroxymethyl- 4-(4-fluorophenyl) piperidine (M3) (Hiemke \& Hartter 2000). Steady-state plasma paroxetine concentrations were achieved after approximately 10 days following 40-mg once daily dose (Mandrioli et al. 2007). Thioridazine is mainly metabolized into mesoridazine and sulphoridazine. Steady-state
Table $9 \%$ Recoveries after application of the proposed method for determination of investigated CNS drugs in real human plasma sample

\begin{tabular}{|c|c|c|}
\hline Drug & $\begin{array}{l}\text { Intraday assay } \\
\% \text { Recovery }_{\text {invivo }}\end{array}$ & $\begin{array}{l}\text { Interday assay } \\
\% \text { Recovery }_{\text {invivo }}\end{array}$ \\
\hline \multicolumn{3}{|l|}{ Fluoxetine } \\
\hline Mean \pm SD & $91.53 \pm 5.11$ & $86.28 \pm 5.27$ \\
\hline \multicolumn{3}{|l|}{ Sertraline } \\
\hline Mean \pm SD & $88.83 \pm 5.38$ & $85.50 \pm 5.947$ \\
\hline \multicolumn{3}{|l|}{ Paroxetine } \\
\hline Mean \pm SD & $76.76 \pm 4.82$ & $75.28 \pm 7.94$ \\
\hline \multicolumn{3}{|l|}{ Thioridazine } \\
\hline Mean \pm SD & $91.53 \pm 5.11$ & $92.26 \pm 2.73$ \\
\hline \multicolumn{3}{|l|}{ Amineptine } \\
\hline Mean \pm SD & $86.29 \pm 6.44$ & $87.41 \pm 3.87$ \\
\hline
\end{tabular}

plasma thioridazine concentrations were achieved after approximately 7 days following four 100-mg doses per day (Vanderheeren \& Muusze 1977). Sertraline is mainly metabolized into N-desmethylsertraline. Steady state plasma concentration level for sertraline and its metabolite were achieved after approximately one week of a $50-\mathrm{mg}$ oncedaily dosing (Package Insert, Zolofi@, Pfizer Inc 1992; Mandrioli et al. 2006). Amineptine is mainly metabolized by beta-oxidation of the side chain, its principle metabolites has the same structure as the parent compound except that its side chain is reduced to five carbon atom (Lachatre et al. 1989). Steady state plasma level is achieved at 8 th day following two $100.0 \mathrm{mg}$ doses per day (Rop Pok et al. 1990).

According to the reported metabolic pathway of all the cited drugs; the proposed method can be used specifically for determination of fluoxetine and sertraline only in presence of their metabolites in plasma because the metabolic products are considered as compounds containing primary

Table 8 Application of the proposed method to the determination of studied drugs in spiked human plasma

\begin{tabular}{|c|c|c|c|c|c|}
\hline \multirow{2}{*}{$\begin{array}{l}\text { Concentration } \\
\left(\text { ngmL }^{-1}\right)\end{array}$} & \multicolumn{5}{|c|}{$\%$ Recovery ${ }^{f}$} \\
\hline & Fluoxetine & Sertraline & Paroxetine & Thioridazine & Amineptine \\
\hline 50 & 97.79 & 100.12 & 102.40 & 99.01 & 100.84 \\
\hline 100 & 98.62 & 97.68 & 99.20 & 99.36 & 101.64 \\
\hline 150 & 103.03 & 103.22 & 97.54 & 100.05 & 102.39 \\
\hline 250 & 99.11 & 98.56 & 99.46 & 97.21 & 98.84 \\
\hline 350 & 98.42 & 100.76 & 98.22 & 101.64 & 99.31 \\
\hline 450 & 101.10 & 99.85 & 101.55 & 99.40 & 99.56 \\
\hline 550 & - & - & 99.72 & 99.25 & 101.61 \\
\hline 650 & - & - & - & 102.19 & 98.76 \\
\hline 750 & - & - & - & - & 100.61 \\
\hline Mean $\pm S D$ & $99.68 \pm 1.99$ & $100.03 \pm 1.92$ & $99.73 \pm 1.73$ & $99.76 \pm 1.565$ & $100.39 \pm 1.33$ \\
\hline
\end{tabular}

${ }^{f}$ Mean of three replicate measurements. 
amino group (as norfluoxetine and norsertraline); which should not interfere upon application of the suggested procedure, while for thioridazine, paroxetine and amineptine, their metabolites can interfere with the determination of the parent drugs because they contain the same function group (secondary or tertiary amine moiety) as well.

So \% recovery of fluoxetine and sertraline in plasma were calculated by using the following equation

$$
\begin{aligned}
\%_{\text {Recovery }_{\text {in vivo }}=} & \left(\text { concentration }_{\text {found }} / \text { concentration }_{\text {taken }}\right) \\
& \times 100
\end{aligned}
$$

Where,

\% Recovery in vivo is \% recovery for drug in real human sample.

Concentration found is concentration of the drug founded in real human sample.

Concentration taken is concentration of the drug reported in real human sample.

While \% recovery of thioridazine, paroxetine and amineptine and their metabolites in plasma were calculated by using the same equation

Where,

$\%$ Recovery in vivo is \% recovery for drug and their metabolites in real human sample.

Concentration found is concentration of the drug and their metabolites founded in real human sample.

Concentration taken is reported concentration of the

drug and their metabolites in real human sample.

$\%$ Recoveries after application of the proposed method for determination of investigated CNS drugs in real human plasma sample by intra and inter day assay are shown in Table 9.

\section{Conclusion}

The proposed spectrofluorimetric method has the advantage of being simple, highly sensitive and low cost method for determination of the investigated antidepressant drugs in pure forms, pharmaceutical formulations, without any interference from common excipients present and with minimum detection limits. Furthermore the proposed method was successfully applied for analysis of the cited drugs in spiked and real human plasma. Therefore, the developed method can be considered as suitable for routine analysis of investigated antidepressant drugs in quality control and clinical laboratories. Also it is suitable for selective determination of fluoxetine and sertraline only without their metabolites in human plasma.

\section{Competing interests}

All authors declare that there is no competing of interest.

\section{Authors' contributions}

Dr Mahmoud M. Omar and Dr. Sayed M. Derayea proposed the idea and design the experimental section. Dr Tamer Z. Attia, Dr. Sayed M. Derayea and Dr Mahmoud M. Omar carried out the experimental parts and participated in sequence alignment and drafted the manuscript. All authors participated in preparation of the discussion and result section. Dr Osama H. Abdelmageed and Dr. Tadayuki Uno revised the final manuscript. Finally all authors read and approved the final manuscript.

\section{Acknowledgements}

The authors express their gratitude to Egyptian government for providing financial support to achieve this paper. Also, the authors express their gratitude to Dr. Monsef Mahfuz a consultant psychiatrist and manager of Minia hospital for psychiatric medicine (Minia, Egypt) for providing the plasma samples.

\section{Author details}

${ }^{1}$ Analytical Chemistry Department, Faculty of pharmacy, Minia University, Minia 61519, Egypt. ${ }^{2}$ Pharmaceutical Chemistry Department, Faculty of Pharmacy, King Abdulaziz University, Jeddah, Kingdom of Saudi Arabia. ${ }^{3}$ Graduate School of Pharmaceutical Sciences, Osaka University, 1-6

Yamadaoka, Suita, Osaka 565-0871, Japan.

Received: 13 March 2013 Accepted: 14 March 2013

Published: 18 April 2013

\section{References}

Atta-Politou J, Skopelitis I, Apatsidis I, Koupparis M (2001) Eur J Pharmaceut Sci 12:311

Basavaiah K, Manjunatha Swamy L, Krishnamurthy G (1999) Chem Pharm Bull 47:1351

Brunswick DJ, Amsterdam JD, Fawcett J, Quitkin FM, Reimherr JF, Beasley CM (2002a) J Affect Disord 68:243

Brunswick DJ, Amsterdam JD, Fawcett J, Quitkin FM, Reimherr FW, Rosenbaum JF, Beasley CM (2002b) J Affect Disord 68:243

Bueno F, Bergold AM, Fröehlich PE (2000) Boll Chim Farm 139:256

Darwish IA (2005) J AOAC INTERNATIONAL 88:38

Darwish IA, Refaat IH (2006) J AOAC INTERNATIONAL 89:326

Delazzeri L (2005) Caderno de Farmácia 21:37

Hiemke C, Hartter S (2000) Pharmacol Ther 85:11

Job P (1964) Advanced Physicochemical Experiments, 2nd edition. Oliner and Boyd, Edinburgh, p 54. Ann. Chem. 1936, 16, 97

Labat L, Deveaux M, Dallet P, Dubost JP (2002) J Chromatogr B773:17

Lachatre G, Piva C, Riche C, Dumont D, Defrance R, Mocaer EV (1989) V Nicot Fundam Clin Pharmacol 3:19

Lemberger L, Bergstrom RF, Wolen RL, Farid NA, Enas GG, Aronoff GR (1985) J Clin Psychiatry 46:14

Mandrioli R, Pucci V, Visini D, Varani G, Raggi MAJ (2002) Pharm Biomed Anal 29:1127

Mandrioli R, Saracino MA, Ferrari S, Berardi D, Kenndler E, Raggi MA (2006) J Chromatogr B836:116

Mandrioli R, Mercolini L, Ferranti A, Furlanetto S, Boncompagni G, Roggi MA (2007) Anal Chim Acta 591:141

Meiling Q, Peng W, Yingshu G, Junling G, Ruonong FJ (2002) Clin Pharmaceut Sci 11:16

Mohamed FA, Mohamed HA, Hussein SA, Ahmed SA (2005) Pharm Biol Ana 39:139

Mohamed GG, Nour El-Dien FAF, Mohamed NA (2007) Spectrochim Acta A68:1244

Nevado JJB, Llerena MJV, Cabanillas CG, Robledo VR, Buitrago S (2006) J Separ Sci 29:103

Nouws HPA, Delerue-Matos C, Barros AA, Rodrigues JA (2006) J Pharm Biomed Anal 42:341

Onal A, Kepekçi SE, Oztunç A (2005) J AOAC INTERNATIONAL 88:490 
Package Insert, Zolofi@, Pfizer Inc (1992). Jan. through analytical profile of drug substances, vol 25, p 443

Parfitt K, Martindale E (2002) The Complete Drug Reference, 33rd edition. Pharmaceutical Press, London, UK

Patel KN, Patel JK, Rathod IS (2009) J Pharm Res 2:1525

Pérez V, Puiigdemont D, Gilaberte I, Alvarez E, Artigas F (2001) J Clin

Psychopharmacol 21:36

Rop Pok P, Spinazzola J, Bresson M (1990) J Chromatogr B532:351

Sbarra C, Negnm P, Fanelh R (1979) J Chromatogr 162:31

Sbarra C, Castelh MG, Noseda A, Fanelh R (1981) Eur J Drug Metab Pharmarmacokin 6:123

The United States Pharmacopoeia XXV and NF XX (2002). American Pharmaceutical Association, Washington, DC

Topic Q2A (1994) Text on validation of analytical procedure. International Conference on Harmonization (ICH)

Topic Q2B (1996) Validation of analytical procedure. Methodology, International Conference on Harmonization (ICH)

Tsaconas C, Padteu P, d'Athts P, Mocaer E, Bromet N (1989) J Chromatogr 487:313

Vanderheeren FHJ, Muusze RG (1977) Eur J Clin Pharmacol 11:135

Zainaghi IA, Lanchote VL, Queiroz RHC (2003) Pharmacol Res 48:217

doi:10.1186/2093-3371-4-5

Cite this article as: Omar et al:: Spectrofluorimetric determination of certain antidepressant drugs in human plasma. Journal of Analytical Science and Technology 2013 4:5.

\section{Submit your manuscript to a SpringerOpen ${ }^{\circ}$ journal and benefit from:}

- Convenient online submission

$\checkmark$ Rigorous peer review

- Immediate publication on acceptance

- Open access: articles freely available online

- High visibility within the field

- Retaining the copyright to your article

Submit your next manuscript at $>$ springeropen.com 